\title{
Cuidado paliativo em Neonatologia: estratégias de enfrentamento da equipe multiprofissional
}

\author{
Palliative care in Neonatology: coping strategis from the multidisciplinary team
}

\author{
Juliana Guimarães de Alencastro Astarita', Cláudia Simone Silveira dos Santos ${ }^{2}$ e \\ Adriane Gonçalves Salle
}

\begin{abstract}
Resumo: $O$ estudo buscou conhecer as estratégias de enfrentamento dos profissionais de uma unidade de Neonatologia em um hospital público e universitário da região Sul do país, frente ao cuidado paliativo neonatal. Foi uma pesquisa qualitativa, do tipo descritiva, em que 18 participantes da equipe multiprofissional (enfermagem, médicos, fonoaudiólogos, fisioterapeutas, assistentes sociais e nutricionistas), com pelo menos 3 meses de trabalho na área, independente da instituição, responderam uma entrevista semiestruturada, entre fevereiro e setembro de 2019, mediante assinatura do Termo de Consentimento Livre e Esclarecido, atentando para os cuidados éticos. Emergiram quatro categorias: Entendimento e sentimentos frente ao processo de morte de um bebê; Percepção sobre o cuidado paliativo com bebês e familiares; Estratégias de enfrentamento diante do cuidado paliativo neonatal; Pensamentos/percepção sobre a atuação em equipe. Dúvidas e pouco conhecimento sobre o conceito do cuidado paliativo, frequentemente confundido com terminalidade, foram identificados. As estratégias de enfrentamento prevalentes foram o suporte social e o afastamento. Destacaram-se a necessidade de compreensão sobre o processo de morte de um bebê e o luto, capacitação da equipe em cuidado paliativo, o desenvolvimento da comunicação mais eficaz entre
\end{abstract}

\footnotetext{
1 Psicóloga, Especialista em Atenção Materno-Infantil, Universidade Federal do Rio Grande do Sul. E-mail: juliana.astarita@gmail.com

2 Psicóloga do Hospital de Clínicas de Porto Alegre, Doutora em Ciências da Saúde: Ginecologia e Obstetrícia (UFRGS). E-mail: csssantos@hcpa.edu.br

3 Psicóloga do Hospital de Clínicas de Porto Alegre, Especialista em Psicoterapia da Infância e Adolescência (CEAPIA). E-mail: asalle@hcpa.edu.br
}

a equipe e criação de protocolos assistenciais para cuidado mais humanizado aos pacientes e famílias.

Palavras-chave: Cuidado paliativo neonatal; Equipe Multiprofissional; Estratégia de enfrentamento.

Abstract: The study sought to understand the coping strategies of professionals in a Neonatology unit in a public and university hospital in the southern region of the country, regardin neonatal palliative care. It was a qualitative, descriptive reaserch, in which 18 participants of the multidisciplinary team (nursing, physicians, speech therapists, physiotherapists, social workers and nutritionists), with at least 3 months of work in the área, regardless of the institution, answered a semi-instructured interview, between February and September 2019, upon signing the Informed Consent Form, paying attention to ethical care. The four categories that emerged were: Understanding and feelings regarding the baby's death process; Perception about palliative care with babies and familys members; Coping strategies regarding neonatal palliative care; Thoughts/perception about teamwork. Doubts and little knowledge about the concepto of palliative care, often confused with terminality, were identified. The prevalent coping strategies were social support and distance. The need to understand the processo $f$ a baby's death and mourning, training of the team 
in palliative care, the development of more effective communication between the team and the creation of care protocols for more humanized care for patiens and families were highlighted.

\section{Introdução}

A prática de cuidado paliativo em crianças e recém-nascidos ainda está em evolução, contando com poucos estudos no Brasil. Segundo o Departamento de Informática do Sistema Único de Saúde, ocorreram no Brasil 18.780 óbitos de crianças até um ano de idade durante 0 ano de 2017 (DATASUS, 2017). As principais causas de óbitos neonatais estão relacionadas à prematuridade extrema, baixo peso ao nascer, malformações congênitas, sepse ou outras complicações durante o período do parto e pós-parto. Esse tipo de cuidado, muitas vezes relacionado à morte e terminalidade, é enfrentado com dificuldade pelo paciente, seus familiares e equipe de saúde (Barbosa et al, 2008).

A Organização Mundial de Saúde (2018) se refere ao cuidado paliativo como uma abordagem que melhora a qualidade de vida dos pacientes, adultos e crianças, e suas famílias que enfrentam problemas associados a doenças potencialmente fatais. Ela aponta para a prática como uma terapêutica que auxilia na prevenção e alívio do sofrimento a partir do manejo correto da dor e do cuidado com os aspectos físicos, psicossociais e espirituais do paciente e seus familiares, com a abordagem em equipe multiprofissional.

Para além das dificuldades da equipe, os pais ou cuidadores sofrem com a descoberta e as manifestações da doença, demonstrando, além dos sentimentos de tristeza e dor pela perda, frágil conhecimento a respeito de cuidados paliativos. Cabe à equipe proporcionar cuidado também à família, o que exige um olhar diferenciado e qualificado, a partir da atuação de uma equipe multiprofissional (Cavalcante et al, 2018).

A partir da prática profissional em uma Unidade de Neonatologia, onde emergiram dificuldades, dúvidas, divergências e entraves relacionados à pratica do cuidado paliativo, surgiu a necessidade de realizar esse estudo. Ele se propôs a discorrer sobre a complexidade do tema, suas dificuldades e 0 sofrimento emocional manifestado pelos profissionais de saúde nas intervenções com bebês em cuidado paliativo, apontando para a importância de uma melhor compreensão acerca do conceito desse cuidado e das estratégias de enfrentamento utilizadas nessas situações. A partir dos resultados descritos, projetos de capacitação dos profissionais podem ser implantados, com vistas a melhorar a qualidade da comunicação entre equipe e família no processo decisório, assim como na aplicação do cuidado paliativo neonatal.

\section{Método}

Trata-se de um estudo qualitativo, com amostra por conveniência, composta por: dois fisioterapeutas, dois fonoaudiólogas, uma assistente social, uma nutricionista, três enfermeiras, três técnicos de enfermagem, três residentes médicos, duas médicas contratadas da unidade e uma professora de medicina chefe de equipe, num total de dezoito participantes, selecionados através de sorteio, respeitando um número minimamente representativo de profissionais que compõem a equipe multiprofissional de uma unidade de Neonatologia de um hospital terciário, público e universitário do sul do Brasil. Foram elaboradas listas com as diferentes especialidades em que os profissio-
Keywords: Neonatal palliative care; Multidisciplinary team; Coping strategies.

nais foram incluídos e posteriormente sorteados. A construção das listas se deu em função do número diferenciado de profissionais nas especialidades. 0 estudo qualitativo investiga significados, motivos, crenças, valores, ou seja, o indivíduo é entendido como parte da realidade social (Minayo, 2008). De caráter exploratório, buscou se aproximar dos fenômenos e fatos para desenvolver, esclarecer e modificar as ideias estudadas e construir hipóteses (Gil, 2007). Os critérios de inclusão foram: profissionais que compõem a equipe multiprofissional em Unidade de Neonatologia, com pelo menos três meses de trabalho na área, independente da instituição. 0 profissional psicólogo não fez parte do estudo por ser o pesquisador.

Foi utilizada uma entrevista semiestruturada como instrumento de pesquisa, elaborada pelas pesquisadoras, contendo dados como: idade, formação profissional e conhecimento sobre cuidado paliativo. As entrevistas foram gravadas em áudio para posterior transcrição e análise. Nas perguntas abertas, o conteúdo foi relacionado à percepção e entendimento dos profissionais acerca do processo de morte de um bebêe suas estratégias de enfrentamento diante de cuidado paliativo neonatal.

A duração das entrevistas foi de aproximadamente uma hora e a coleta dos dados se deu no período de fevereiro a setembro de 2019, em uma sala com privacidade, na Unidade de Neonatologia. As respostas foram gravadas digitalmente em áudio, com o consentimento dos participantes, e posteriormente transcritas na íntegra para serem analisadas, garantindo assim a fidedignidade das informações. 0 material transcrito foi salvo em um arquivo com senha para proteçãa dos dados e ficará armazenado por 5 anos pelo pesquisador responsável. Após a concordância do participante, foi marcada a entrevista onde foi firmado o Termo de Consentimento Livre e Esclarecido (TCLE). Para garantir o anonimato dos participantes e facilitar a leitura e interpretação dos resultados, as entrevistadas foram identificadas por participantes (P) e seguidas de números conforme a ordem de realização das entrevistas.

A análise dos dados coletados foi realizada através do método de Análise de Conteúdo proposta por Bardin (2011), que permite abordar de forma sistemática a complexidade e subjetividade do tema abordado nos discursos diversificados dos participantes, onde se observa a ausência ou presença do conteúdo estudado. Esse processo compreende três fases distintas: a pré-análise, que implica na organização e ordem dos dados após a coleta, para fins da transcrição na íntegra, bem como as unidades de registros e a forma de categorização. A fase seguinte é constituída pela exploração do material, contendo o processo de codificação dos dados, classificação e agregação dos achados. Ea terceira fase, que é composta pela análise dos dados coletados, articulada à fundamentação teórica.

A pesquisa seguiu as determinaç̃ões das Diretrizes e Normas Regulamentadoras de Pesquisas Envolvendo Seres Humanos, conforme a Resolução do Conselho Nacional de Saúde n466 de 2012 (Conselho Nacional de Saúde, 2012). 0 projeto foi analisado e aprovado pelo Comitêde Ética em Pesquisa do Hospital de Clínicas de Porto Alegre (n 2019-0009) e pela Plataforma Brasil (CAEE 05538818.9.0000.5327). 


\section{Resultados e discussão}

Os dados obtidos através da análise sociodemográfica foram os seguintes: a amostra foi composta somente por profissionais do sexo feminino (sorteio), com idades variando entre 27 e 59 anos, o tempo de formação num intervalo de 3 a 34 anos e tempo de prática em Unidade de Neonatologia entre 1e 24 anos. 0 maior número de entrevistadas foi nas categorias profissionais de medicina e enfermagem, profissões de maior representatividade na unidade.

A partir das narrativas emergentes nas entrevistas, surgiram questões em comum com significativa importância para este estudo, o que permitiu a análise do conteúdo das falas através de sua categorização. As categorias foram denominadas da seguinte forma: 1) 0 processo de morte de um bebê; 2) Cuidado paliativo com bebês e suas familias; 3) Estratégias de enfrentamento em cuidado paliativo neonatal e 4) Percepção acerca da atuação em equipe multiprofissional em casos de cuidado paliativo neonatal. Na segunda categoria, emergiu uma subcategoria que abarca a Compreensão do conceito de cuidado paliativo.

Dentre os participantes, seis apresentaram dificuldades em diferenciar os conceitos de cuidado paliativo e terminalidade. Verificamos que, em todas as entrevistas, emergiram sentimentos e estratégias de enfrentamento frente à situação de óbito. As estratégias de enfrentamento, definidas por Lazarus e Folkman (1985) são respostas frente a situações de estresse vivenciadas. Essas respostas podem ser focadas na emoção ou focadas no problema, e as estratégias consistem em mudanças de comportamento com a finalidade de resolver situações espećificas, sejam internas ou externas. Ainda segundo Straub (2014) as estratégias de enfrentamento são capazes de sofrer modificações ao longo do desenvolvimento do indivíduo e das situações vivenciadas. No inventário, adaptado ao Brasil por Savóia, Santana \& Mejias (1996), os autores as dividem em "respostas emocionais" e"focadas no problema", classificando-as em oito fatores, sendo esses: confronto, afastamento, autocontrole, suporte social, aceitação de responsabilidade, fuga-esquiva, resolução de problemas e reavaliação positiva. A análise das estratégias de enfrentamento dos profissionais foi baseada nessas classificações.

Passaremos agora a apresentar as categorias que emergiram das entrevistas.

Na categoria 1 - 0 processo de morte de um bebê - os achados mostraram que para acessar a percepção e 0 entendimento da equipe multiprofissional em situações de cuidado paliativo neonatal, é importante compreender como cada profissional percebe e enfrenta o processo de morte de um bebê. Nas falas dos profissionais, o processo de morte de um bebê foi compreendido pela maioria como algo muito difícil de lidar, destacando 0 entendimento de que a morte de uma criança maior, que teve convívio com a família, representa maior sofrimento para os pais do que a morte de um bebê, momento em que a mãe ainda não estaria tão apegada ao filho: "Eu acho queé pior porque a mãe já vivenciou aquela criança em casa, enfim... ou muito tempo no hospital... eu pelo menos percebo que quanto mais tempo a mãe vivencia com o bebê, pior é quando recebe o resultado" (P16).

A literatura confirma que a percepção dos pais é contrária à da equipe profissional, uma vez que a perda do filho, seja ele bebê ou maior, desperta muito sofrimento no casal. Além disso, o fato do não reconhecimento social da perda de um recém-nascido intensifica desnecessariamente esse sofrimento, minimizando ou invalidando a dor dos pais (Melo \& Vaz, 2019).

Três participantes referiram que uma das dificuldades da equipe é a associação da morte com o final da vida, e não com o momento do nascimento. Outros profissionais identificaram a morte do bebê de forma súbita como mais mobilizadora e traumática para os pais do que um processo de morte por adoecimento. Nesse sentido Araújo e Belém (2010) apontam para dificuldade dos profissionais em lidar com a morte, que advém da não aceitação dessa como parte natural do ciclo da vida, gerando sentimentos de frustração, fracasso e incapacidade. Essas dificuldades são evidenciadas pelo despreparo dos profissionais com o momento da morte de bebês. Segundo os autores, esse despreparo origina-se na formação acadêmica, onde não há espaço na educcção em saúde para que se fale sobre a morte como algo natural, como foi evidenciado pela fala a seguir: "É muito triste porque bebês não foram feitos para morrer" (P11).

Uma participante se mostrou ambivalente diante do processo de morte de um bebê, não conseguindo expressar o que de fato sentia ou entendia sobre esse momento. 0 que na prática, pode gerar intervenções e comportamentos mais frágeis ou inadequados diante do manejo de situação de perda para com os pais. Independentemente, cada participante referiu como um momento de muita tristeza para a família, mas também para elas como profissionais que atendem esses casos. Kóvacs (2010) refere que a morte é vivenciada a partir de diferentes concepções, e sentida de forma individual por cada sujeito. A percepşão da morte é atravessada pela história pessoal, de vivências anteriores de perda e luto de questões culturais. No caso da equipe multiprofissional, acrescenta-se a formação acadêmica e experiência profissional a isso. Deparar-se com a morte de um paciente suscita reflexões acerca de sua própria finitude. Em seu estudo de Silva (2017), a morte de um bebê é experienciada pela equipe como um momento obscuro e incompreensível, pois modifica 0 percurso natural da vida, como é ilustrado na fala: "A morte de um bebê ela contraria né, ela éo reverso da moeda, éo lado negro desse momento, porque contraria toda a expectativa né, de perpetuação da história da família, da expectativa de todo um cuidado" (P4).

Almeida (2016) refere que a morte de um recém-nascido é muito mais dificil para a equipe multiprofissional aceitar, significando uma brusca interrupção no ciclo de vida e história daquela família. Quatro das dezoito participantes referiram a perda de um bebê como algo mais fácil de enfrentar ou "aceitar" quando a morte ocorre por algum diagnóstico de incompatibilidade com a vida ou prognóstico ruim. Observa-se que a crença de que a morte nesse contexto evita maior sofrimento ao bebê conforta os profissionais e auxilia no enfrentamento da perda, possibilitando a continuidade do cuidado: "0 processo de morte de um bebê é bem complicado né, porque em geral eu vejo assim que as pessoas nunca conseguem associar o bebê ao fim da vida né. $E$. sempre um processo associado ao início da vida..." (P8).

Evidencia-se que a percepção sobre o processo de morte de um bebê, para os profissionais da equipe multiprofissional é de difícil compreensão e enfrentamento. As equipes sentem-se despreparadas para lidar com a morte e seus desdobramentos, faltando-lhes instrumentos, técnica ou suporte psicológico que auxilie e oriente frente a essa situação. Gonçalves \& Santos (2019) apontam a necessidade de iniciativas que promovam o preparo de profissionais, para que eles possam identificar os sentimentos mobilizados pela morte de um bebê, oferecendo subsídios e ferramentas que possam lançar mão para lidar com tais sentimentos.

A fim de identificar como as participantes se sentiam frente a esses casos, na categoria 2 - Cuidado paliativo com bebê e suas famílias, foi questionado sobre como era atender esses bebês. Duas participantes disseram 
que se sentiam desconfortáveis. Despontaram nos discursos sentimento de tristeza, descrevendo momentos em que tentavam se colocar no lugar dos pais. Outras duas apontaram para sua própria experiência da maternidade como algo que mobilizou mais sentimentos e dificultou o processo de cuidado. Segundo Batthika, Carvalho \& Kopelman (2014), a equipe multiprofissional é afetada pela presença dos pais na unidade, e a capacidade empática gera sentimentos identificatórios, seja com os pais ou com a criança. Ao colocarem-se no lugar da família, os profissionais revivem suas próprias perdas e se confrontam com o medo de perder seu próprio filho. A experiência da própria maternidade intensifica tanto esse medo como a identificação com a figura da mãe que está perdendo seu bebê: "Um caso de um paciente, eu tava voltando da minha licença maternidade e eu acabei me apegando também, sofri um pouco com a perda também" (P15).

Nessa ação de maior proximidade aos sentimentos dos pais, sete participantes referiram que um cuidado mais humanizado e próximo da família Ihes auxilia a lidar com a situação. Atos como: proporcionar os cuidados básicos e possíveis ao bebê, assim como prover apoio emocional e esclarecer dúvidas, é referido como algo que alivia suas angústias frente à proximidade da morte. 0 modo de cuidar envolve múltiplos fatores, segundo Silva (2017), desde crenças pessoais até a qualificação do profissional, especialmente na forma como aquele indivíduo lida com situações de final de vida. Esse cuidado desempenhado pela equipe reflete diretamente no modo como a família irá vivenciar esse momento, permitindo ressignificações (Silva et al, 2017).

Batthika, Carvalho \& Kopelman (2014) afirmam que os profissionais reforçam a importância de os pais estarem bem informados sobre o quadro de saúde do seu bebê, porém destacam que isso estaria relacionado a uma descarga de angústia da equipe frente ao cuidado paliativo, por suscitar sentimentos de fracasso e incompetência. Isso também emergiu durante as entrevistas, pois a comunicação com a família foi citada como um fator que permitiu o alívio das angústias da equipe. A impossibilidade de curar ou salvar o recém-nascido, bem como as limitações das tecnologias para esses fins pode acabar por mobilizar sentimentos de fracasso e impotência no profissional, diante da possibilidade da morte no início da vida.

Assim, seis participantes referiram utilizar o distanciamento emocional como algo que lhes favorecia exercer o cuidado com os pacientes, percebendo-se a dificuldade de algumas profissionais de entrar em contato com seus sentimentos relacionados ao tema. Alves, França \& Melo (2018) descrevem esse distanciamento emocional como forma de evitar acessar seus sentimentos e seu próprio sofrimento diante da morte, ao negar a condição de saúde da criança, dessa forma sendo possível desempenhar o cuidado necessário ao paciente: "Tento me preservar o máximo que dá, assim, não me envolver até como mecanismo de barreira... eu tento lidar com aquilo friamente" (P10).

Cinco participantes apontaram para dúvidas e manifestaram inseguranças no manejo de bebês em cuidado paliativo e nas condutas relacionada à sua profissão, sentindo que um bebê nesse tipo de cuidado muitas vezes não possibilita uma intervenção especifica dentre sua atuação profissional. Elas verbalizaram dúvidas se 0 bebê deve ser alimentado, estimulado, manejado e, especialmente, o que comunicar aos pais sobre sua especialidade nesse contexto, apontando para a necessidade de um maior alinhamento e integração da equipe como um todo para que ocorra uma comunicação eficaz com as famílias.

Frente a isso, Silva et al (2017) reforçam a importância do processo de tomada de decisão não ser centrada na equipe médica, bem como a necessidade de elaboração de um protocolo ou plano de cuidado que inclua toda a equipe assistente. Essas questões, somadas ao pouco espaço para diálogo, culminam em entraves na implantação do cuidado paliativo. Mancini (2014) aborda a importância de reuniões multiprofissionais sistemáticas, para potencializar a discussão do caso e coesão das condutas assistenciais. A dificuldade de partilha de informações com outros profissionais da equipe ocorre pela falta de clareza da atuação desses no processo decisório. Desta forma, profissionais essenciais no cuidado, como enfermeiros e técnicos de enfermagem que permanecem mais tempo próximo da família, não são convidados a participarem das discussões em equipe, gerando insegurança e ruídos na comunicação.

Apesar disso, quatro profissionais expressaram gostar de atuar com cuidados paliativos, afirmando que, pelo tempo de profissão e prática, consideraram-se capacitadas para manejar e conduzir tais situações. A necessidade de maior discussão e integração entre equipe apareceu nas suas falas, bem como treinamento dos profissionais envolvidos.

Duas participantes apontaram dificuldades, como a resistência em implantar a conduta de cuidado paliativo. Três profissionais identificaram necessidade de maior empatia em relação aos familiares, apontando isso como falha na assistência ao paciente. Diversos autores discorrem sobre as dificuldades no processo de tomada de decisão e implantação de cuidados paliativos neonatais. Através do seu estudo, Silva (2018) identificou que os principais fatores são relacionados à inexistência de protocolos, às barreiras na comunicação, à falta de discurso coeso, aos conflitos entre profissionais de opiniões divergentes, à falta de sensibilização e formação na área, assim como os medos e as dificuldades da equipe em lidar com os sentimentos de fracasso e impotência mobilizados pelo cuidado paliativo:

A gente na neonatologia trabalha muito com a vida, então a gente tá muito preparado a cuidar e fazer tudo pela vida... Porque muitas vezes tem a ver com a nossa incapacidade da equipe de perceber que esse nenê é um paciente de cuidado paliativo e oferecer esse tipo de proposta mais precocemente, (P18).

Em um estudo realizado por Rocha et al (2015) com 6 profissionais de enfermagem acerca de sua experiência frente ao cuidado paliativo de neonatos, identificou-se sentimentos de fracasso, tristeza, e impotência, bem como sentimento de fragilidade e sofrimento por não poder curar o bebê. Tais achados vão de encontro aos sentimentos identificados nas entrevistas conduzidas, como angústia, tristeza e dificuldades na comunicação com os pais. Neis (2018) refere que tais sentimentos devem ser trabalhados internamente, de modo a prevenir maior sofrimento aos profissionais e evitar julgamentos e ocasionais entraves no relacionamento entre equipe e família.

Diante do questionamento de como seria para as participantes atuar com cuidado paliativo com bebês e suas famílias, surgiu uma subcategoria (subcategoria 1: Compreensão acerca do conceito de cuidado paliativo) revelando conteúdo relacionado ao conceito deste cuidado. Cinco das dezoito profissionais entrevistadas conheciam o conceito de cuidado paliativo pela Organização Mundial da Saúde (OMS), apesar de não saber citá-lo: "Pra mim cuidado paliativo é que tu dá assim conforto, fazer todos os cuidados pra melhorar a qualidade de vida que aquele bebê vai ter, até o momento... Até chegar o fim da vida" (P8). 
Quando questionadas sobre o cuidado paliativo, a maioria das participantes fez referência a cuidados de conforto e qualidade de vida diante da terminalidade e do momento do óbito. Demonstraram dúvidas acerca do conceito de cuidado paliativo, por vezes indicando-o como uma conduta não ativa. No entanto, cinco participantes afirmaram conhecer o conceito de cuidado paliativo pela OMS (2018), referindo um cuidado individualizado e integral, que respeita a evolução natural da doença. Em alguns momentos foi possível identificar dificuldades em separar o momento da implantação do cuidado paliativo do momento da morte. Diversos estudos, incluindo Harrop \& Edwards (2013) e Neis (2018) destacam a associação do cuidado paliativo com a morte e momentos finais de vida, apesar de saberem sobre os benefícios e importância na prática. Essa associação pode implicar em uma adoção tardia desse cuidado, quando idealmente a prática do cuidado paliativo precoce é importante devido ao tempo necessário para a construção de uma relação entre equipe e família e de um plano de cuidado adequado.

Neis (2018) salienta que a insistência das equipes médicas pelo tratamento curativo se dá devido à busca de uma certeza total e concreta do prognóstico, muitas vezes empreendendo em medidas fúteis. Essa insistência perpassa o entendimento dos profissionais sobre os objetivos do cuidado paliativo: "Às vezes as pessoas esquecem que pode chamar antes o cuidado paliativo, não é na hora da morte e também não é não fazer nada" (P11).

Foi possível identificar, a partir das verbalizações das participantes, que há uma dificuldade em discernir o que é cuidado paliativo e de que forma é possível aplicá-lo. Assim como nesse estudo, Silva (2017) também identificou em seu trabalho divergências na compreensão do conceito, em que profissionais de saúde sentiam necessidade de formação adequada sobre os princípios do cuidado paliativo.

Das dezoito participantes, doze apontaram possuir algum curso ou capacitação sobre cuidado paliativo, revelando uma falha na educação em saúde. Sugeriram que a equipe multiprofissional recebesse formação voltada aos princípios e filosofia do cuidado paliativo, com a introdução de temas relativos à limitação terapêutica, reflexões éticas, comunicação e elaboração de um plano de cuidado como forma de melhorar o cuidado a pacientes fora da possibilidade de cura.

De forma a identificar os recursos e as estratégias de enfrentamento utilizadas pelas profissionais de saúde no manejo de bebês em cuidado paliativo e suas famílias, foi questionado de que forma a participante agia para se sentir melhor após identificar situações de maior mobilização. Assim surgiu a categoria 3 - Recursos e estratégias de enfrentamento da equipe frente ao cuidado paliativo neonatal.

Muitas das entrevistadas tiveram reações defensivas frente ao questionamento "você identifica situações em que lhe mobilize mais no cuidado a esses pacientes"? A maioria respondeu que sempre se mobilizava diante desses casos, demonstrando dificuldade de compreensão da pergunta.

Durante as entrevistas, apenas uma participante identificou o momento específico que se sentia mais mobilizada, indicando a primeira conversa com a família sobre o prognóstico e indicação de condutas de cuidado paliativo: "Eu acho que quando a gente vai ter a primeira conversa assim, quando a gente vai falar sobre o prognóstico pros pais, ésempre o momento mais difícil" (P14).

Cinco entrevistadas apontaram para a necessidade de maior contato com as famílias, procurando reforçar a qualidade do atendimento, segurança e conforto aos familiares daquele bebê como forma de enfrentar a situação.
Comentaram sobre auxiliar a família a enfrentar a proximidade do momento da perda. Essa estratégia aponta para um enfrentamento focado na resolução de problemas: "Converso com os familiares, tento dar um conforto, Deus que sabe a melhor escolha, enfim, sempre oriento para se apegar no que acredita, na religião que acredita, e conversar com pessoas, pedir força né, ter fé" (P15).

Duas participantes disseram utilizar da religiosidade como estratégia de enfrentamento, referindo que através da crença na religião sentiam maior conforto, ao pensar que aquela situação ocorria por um motivo e um propósito, ainda que não compreendido pelos indivíduos envolvidos. Segundo Lazarus \& Folkman (1985), estratégias de religiosidade enquadram-se na categoria de reavaliação positiva como forma de tolerar os afetos desagradáveis mobilizados pela situação. Nesse contexto, também surgiu o autocontrole como estratégia de enfrentamento, buscando vislumbrar os aspectos positivos que poderiam emergir nesse contexto:

"Eu acho que a situação religiosa influencia nisso também, né. Eu consigo através dessa questão da religião, que é importante assim, no sentido de que aquilo não tá acontecendo por acaso...aquilo ali tá acontecendo por alguma razão, e algum ensinamento" (P7).

Barros \& Gonçalves (2019) também identificaram o uso da religiosidade como estratégia de enfrentamento diante da morte de um paciente, aparecendo como algo que proporciona conforto frente à perda e que dá sentido ao trabalho do profissional. Outros estudos (Arrieira et al, 2018) apontam para a espiritualidade como o verdadeiro sentido do cuidado paliativo, por trazer maior compreensão das ações e princípios desse cuidado, auxiliando na ressignificação das condutas dos profissionais. Nesse sentido, a religiosidade e a espiritualidade aparecem como um recurso terapêutico para a humanização do cuidado, sendo relevantes para ações paliativistas por serem capazes de promover reflexões sobre a morte e até mesmo sua aceitação, algo considerado um paradigma a ser enfrentado pelos profissionais que tem como profissão a luta pela vida.

Três participantes destacaram a necessidade de focar no atendimento a outros pacientes em que há investimento terapêutico e possibilidade de retorno, evitando pensar sobre o bebê adoecido em cuidado paliativo. Em seis entrevistas foi identificado o afastamento como estratégia de enfrentamento, buscando atender aquele paciente quando estiver desacompanhado de familiares, ou não pensar no contexto de perda, de modo a evitar entrar em contato com o sofrimento dos pais diante do quadro de saúde do seu bebê: "Eu continuo trabalhando né. Eu converso com alguns familiares, eu tento pensar em outras questões boas assim, pacientes que possam dar retorno, não foco naquela questão muito triste, porque eu sei que não tem muito que fazer" (P1).

Segundo Oliveira (2015), há uma cultura hospitalar onde os profissionais não devem se envolver emocionalmente com os pacientes, sendo visto como um bom profissional aquele que reprime seus sentimentos e vivências, afastando-se do cenário da perda. Esse afastamento pode ser tanto físico quanto emocional, ao se distanciar do leito do bebê no momento de maior angústia. A autora refere que uma das dificuldades do cuidado paliativo neonatal é a negação das emoções vivenciadas pelos profissionais, pois ela pode interferir e prejudicar a dinâmica do cuidado, no momento em que os esforços para se proteger levam a mecanismos de defesa que podem privar o paciente e a família de um atendimento qualificado e humanizado. 
Três participantes falaram sobre procurar os colegas da equipe para conversar, discutir o caso ou desabafar, como um ato que auxilia a enfrentar a perda do bebê, momento em que se permitiam chorar. Duas participantes relataram conversar com familiares ou companheiros sobre sua vivência como modo de lidar com a angústia, buscando o suporte social como enfrentamento: "A gente acaba conversando, assim, com o restante da equipe né, com os colegas que tão trabalhando junto, e discute o caso, e discute a situação toda, dá uma choradinha e daqui a pouco dá uma melhorada" (P9).

Foram identificadas respostas ambivalentes e incertas sobre o que é esperado sentir e como agir com bebês em cuidado paliativo. Assim, foi possível observar diferentes estratégias de enfrentamento, que por vezes se contradiziam em seus discursos. Barros \& Gonçalves (2019) em um estudo com profissionais da enfermagem reiteram que a equipe vivencia sentimento de ambivalência frente à terminalidade em crianças, dividindo-se entre seu desejo de prestar cuidados e o sofrimento que isso implica.

$\mathrm{Na}$ categoria 4 - Atuação da equipe multiprofissional em cuidado paliativo neonatal, no que tange à atuação em equipe multiprofissional, a maioria das participantes respondeu essa questão como relacionada à atuação da psicologia especificamente. Outras apontaram para a atuação do serviço social também. Foi unânime a concordância de que a atuação em equipe multiprofissional é muito importante como forma de suporte às famílias e contribuição com a equipe. Sete das dezoito participantes utilizaram de palavras como "essencial" e "fundamental" para definir o que achavam da atuação multiprofissional, apontando a atuação em equipe como algo necessário para uma prática mais adequada do cuidado paliativo. Essas opiniões e conceitos vão ao encontro com o que é citado na literatura a respeito da atuação multiprofissional em cuidado paliativo.

Silva (2017) reforça a importância da equipe multiprofissional no processo de tomada de decisão em cuidado paliativo e sobre as reuniões multiprofissionais, como forma de agregar diferentes saberes na construção de um plano de cuidados individualizado. Mancini (2014) reitera a necessidade de reuniões multiprofissionais regulares, de modo a promover discussões do caso e reflexões sobre o cuidado, possibilitando uma comunicação coesa e linear a partir de um funcionamento saudável entre os profissionais da equipe, reduzindo, assim, seu potencial de conflitos: "Ajuda muito né, e acho essencial, acho maravilhosa a ideia. São a nossa base né, pra gente, como que se diz, o colchão onde a gente vai eventualmente se desequilibrar e vocês estão ali pra gente se segurar" (P4).

Nessa categoria, algo aparente também nas anteriores, duas participantes apontaram para a necessidade e desejo de que fosse disponibilizado um espaço, dentro da equipe, onde fosse possível falar sobre as situações vivenciadas e os sentimentos emergentes na assistência frente a cuidado paliativo e a perda.

De acordo com o que foi informado ao longo das entrevistas, percebe-se nos discursos o desejo de uma escuta individualizada e de acolhimento por parte das participantes. A atuação da psicologia na unidade emerge como algo necessário. Segundo Kóvacs (2010), o profissional de saúde que trabalha com o sofrimento em diversas esferas, experimenta sentimentos de frustração e perda pelo paciente que cuidava, o que gera o luto não reconhecido. Em função da dinâmica da área, a equipe precisa seguir com suas tarefas, não sendo autorizada a buscar um espaço para a elaboração do luto pelo paciente. Não há tempo ou espaço para a elaboração ou para que possam compartilhar suas emoç̃es, por vezes podendo surgir a crença de que são merecedores de tais sentimentos ruins, havendo uma sobrecarga afetiva que os predispõe ao adoecimento.

Nesse contexto, o psicólogo atua como facilitador do processo de tomada de decisão, identificando fontes de estresse e realizando intervenções que favoreçam a adaptação ao adoecimento. Além disso, auxilia promovendo estratégias de enfrentamento mais adaptativas, facilitando a validação e expressão de sentimentos e a clara comunicação entre equipe e família, aspecto essencial ao cuidado paliativo. 0 psicólogo poderá intervir com a equipe auxiliando no enfrentamento do estresse proveniente do trabalho por meio de treinamentos, reuniões, rodas de conversa e grupos de apoio, de modo a facilitar a verbalização de sentimentos e angústias relacionadas às perdas vividas no ambiente de trabalho (Martinho, Pilha, \& Sapeta, 2015). Assim, devem ser trabalhados temas como comunicação de más notícias, aspectos do luto e do processo de luto antecipatório, de modo a proporcionar momentos de reflexão e auxiliar os profissionais na elaboração de estratégias de enfrentamento diante de suas próprias emoçoes, e frente às emoções dos familiares dos pacientes (Inácio et al, 2015). 0 profissional de psicologia também deve educar a equipe acerca da dinâmica afetivo-emocional dos pais em momentos diferentes do processo de adoecimento do bebê, muitas vezes sinalizando os profissionais acerca dos estágios do luto em que os pais se encontram naquele momento (Saporetti et al, 2012).

O psicólogo também possui um papel importante no processo de comunicação de más notícias, como parte da equipe e auxiliando os familiares no enfrentamento e compreensão do cuidado paliativo. Um estudo conduzido por Lima et al (2019) sobre comunicação de más notícias em cuidados paliativos em Oncopediatria, realizada com familiares acompanhantes de crianças e adolescentes com diagnóstico oncológico, ressalta a importância de uma estrutura norteadora do processo de comunicação. Os autores citam a criação de protocolos assistenciais, e ressaltam que devem ser consideradas as singularidades de cada caso e família, considerando a estrutura como norteadora do processo de comunicação, e não um fator limitador. Eles reforçam que a comunicação de más notícias se dá em um processo, iniciando com uma retomada do caso, até a comunicação da má notícia, de forma a possibilitar melhor compreensão, e que a comunicação deva ser clara e assertiva, em ambiente reservado ao familiar, possibilitando a expressão emocional.

Os autores salientam que 0 ato de comunicar más notícias é marcado por ambivalência e sentimentos de ambas as partes, e requer capacidade empática do comunicador, sendo uma habilidade difícil e que exige aprendizado e treinamento. Diante dessa necessidade, compreende-se a importância do processo de educação em saúde incluir a comunicação de más notícias como habilidade e competência técnica a ser aprendida. (Lima et al, 2019).

Nos discursos das participantes, foi possível observar a implantação da residência multiprofissional na unidade como agente mobilizador de reflexões a respeito da atuação dos profissionais não médicos como parte integrante da equipe. Uma participante apontou para a inclusão dos residentes de diferentes formações como um processo que agrega conhecimento e inovação à assistência:

"Eu penso que é muito importante a equipe multiprofissional estar bem sintonizada, porque no momento que a família vê que uma peça não ta funcionando bem, eles ficam mais fragilizados e ficam inseguros, então eu acho que a equipe multiprofissional é muito 
importante. A psicologia, a enfermagem, a equipe médica, o serviço social, enfim todas as profissões que estão trabalhando em cima daquele bebê... entrando em acordo assim em relação com todas as condutas e quando conversar com a familia né. Falar assim a mesma linguagem e sempre seguir pro mesmo caminho," (P8).

Foi citada por duas das dezoito participantes a importância da participação da equipe, como um todo, nas reuniões de cuidado paliativo, especialmente quando se incluem os familiares. Porém essa integração foi mencionada como algo muito incipiente, que necessita de estímulo, estudo e reforço, dessa forma sendo al go benéfico para a assistência aos familiares e aos bebês. Neis (2018) discorre sobre essa questão, referindo que a comunicação clara entre todos os profissionais envolvidos na assistência é prioridade, desde seu envolvimento com a família até a compreensão a respeito das condutas definidas para o paciente, de modo a evitar que a falta de compreensão e ruídos na comunicação prejudiquem a família.

Por fim, a proposta inicial de investigar as estratégias de enfrentamento utilizadas pela equipe multiprofissional de uma Unidade de Neonatologia em casos de indicação de cuidado paliativo para um bebê, tema tão complexo, destaca a importância de se escutar a equipe multiprofissional para que essa possa melhor intervir na paliação em Neonatologia. Para al guns participantes, fica evidente a necessidade de não tomar contato com seus próprios sentimentos, uma vez que o trabalho segue diariamente na unidade, bem como o pedido de capacitações no tema.

Assim, se faz necessário o desenvolvimento de ferramentas que promovam melhor comunicação entre equipe e familiares de bebês que estão em cuidado paliativo, bem como o desenvolvimento de estratégias de enfrentamento mais adaptativas nesse cenário, que possam evitar um adoecimento do profissional e possibilitar um cuidado integral e humanizado ao paciente e sua família.

\section{Considerações finais}

Esse estudo possibilitou refletir sobre a percepção e a compreensão dos profissionais da equipe multiprofissional de saúde frente ao cuidado paliativo com bebês. Foi observado que a indicação de cuidado paliativo para bebê, bem como seu processo de morte, implica em sentimentos de impotência, perda e frustração na equipe multiprofissional, gerando sofrimento emocional. Sabemos, através da literatura, que os profissionais que trabalham com Neonatologia manifestam maior dificuldades em compreender e lidar com questões relacionadas ao cuidado paliativo e terminalidade. 0 presente estudo corroborou com essas afirmativas. Contribuindo para essas dificuldades, foi observado que a equipe multiprofissional tem a crença de que a morte de um bebê seria menos traumática para os pais do que uma criança maior, aspecto que minimiza o sofrimento dos pais e suscita um luto não reconhecido. Entendemos que essa seja também uma estratégia de enfrentamento por parte da equipe, uma vez que o afastamento emocional foi uma das estratégias utilizadas pela maioria das participantes.

Sabe-se, de antemão, que as situações de perda e luto causam sofrimento para a equipe, que tem suas singularidades, individualidades, crenças, tabus. Somado a isso, as expectativas com relação à cura do bebê, os momentos de impotência, o entendimento de cada um sobre o prolongamento ou não da vida numa etapa em que a vida está iniciando. Tudo isso mostra a fragilidade da equipe e da família. E por isso, também a dificuldade em conversar sobre paliar em neonatologia. Para isso, destacamos a necessidade de uma comunicação efetiva, pois más notícias somente serão melhor compreendidas se forem ditas de maneira clara, efetiva, objetiva, mas não menos afetiva.

As participantes evidenciaram dúvidas e escasso conhecimento em relação ao conceito e aplicabilidade do cuidado paliativo neonatal, apontando para uma falha da formação em saúde. Foi observada uma associação de cuidado paliativo com terminalidade e cuidados em fim de vida, algo que incorre em entraves no cuidado. Além disso, as incertezas e o medo dos pais, mobilizados pela possibilidade da perda do filho, são de difícil enfrentamento pela equipe. Foi manifestado despreparo no manejo do processo de morte de um bebê, momento no qual sabe-se que muitas vezes são acionadas as próprias vivências de perdas pessoais e crenças relacionadas à finitude. Nesse sentido, é fundamental ressaltar a cultura da busca pela cura na formação em saúde gera um obstáculo para a compreensão do conceito de cuidado paliativo, particularmente em um momento associado ao início da vida, al go ressaltado pela literatura e identificado no presente estudo.

Quanto às estratégias de enfrentamento utilizadas pela equipe multiprofissional, o suporte social foi o mais utilizado, apontando principalmente para a busca de apoio nos colegas de trabalho, familiares e para a religiosidade. 0 afastamento da situação de cuidado paliativo foi a segunda estratégia mais prevalente que emergiu das entrevistas, mostrando a necessidade de um distanciamento emocional como ação protetiva diante do cuidado com esses bebês e suas famílias. A estratégia de resolução de problemas também foi identificada, uma vez que as profissionais agem focando no cuidado necessário a ser desempenhado e necessidade de proporcionar suporte à família como algo que thes auxilia a lidar com a situação.

A atuação em equipe multiprofissional foi referida como muito importante para o processo de cuidado paliativo em bebês, embora tenha sido identificada uma confusão entre a atuação da Psicologia e atuação em equipe multiprofissional. Também se destacou o desejo das participantes de suporte emocional e psicológico voltada para as necessidades da equipe, apontando para a importância de momentos em que pudessem falar sobre as perdas. Nesse sentido, é importante salientar que a ausência desse espaço de fala e escuta reforça o luto não reconhecido dos profissionais da equipe, que também sofrem pela perda de seus pacientes. Necessitam que seja viabilizada a elaboração dessas perdas para evitar um adoecimento físico e psíquico. A subjetividade do profissional de saúde, seus sentimentos e emoções frente à fragilidade e a realidade do adoecimento e perda de seus pacientes devem ser considerados diante do cuidado de um bebê em cuidado paliativo, bem como a necessidade de elaboração de um processo de luto próprio do profissional.

Para finalizar, a relevância dessa pesquisa se dá pela importância do estudo sobre o cuidado paliativo neonatal e sua complexidade para o campo da Psicologia e da Saúde como um todo. Reforça-se a necessidade de outros estudos a fim de promover reflexões acerca do tema e das dificuldades encontradas, possibilitando uma melhora na assistência, na comunicação e na relação entre equipe e família. Foi possível, a partir desse estudo, fomentar a discussão do tema na equipe multiprofissional e dar início a um planejamento de formação em cuidado paliativo para profissionais da Neonatologia. Dessa forma, é importante considerar que o psicólogo contribui para o trabalho em equipe e para a construção de um cuidado mais humanizado ao bebê e suas famílias. 


\section{Referências}

Almeida, F. A, Moraes, M.S., \& Cunha, M. L. R. (2016). Cuidando do neonato que está morrendo e sua família: vivências do enfermeiro da terapia intensiva neonatal. Revista da Escola de Enfermagem USP, (n.esp): 122129. Recuperado de: http://www.scielo.br/pdf/reeusp/v50nspe/ pt_0080-6234-reeusp-50-esp-0122.pdf

Alves, A. M. F., França, M. L. R., \& Melo, A. K. (2018). Entre o nascer e o morrer: cuidados paliativos na experiência dos profissionais de saúde. Revista Brasileira de Promoção de Saúde, Fortaleza, 31(1): 1-10, jan./mar. Disponível em:http://periodicos.unifor.br/RBPS/article/view/6712

Araújo, S. A. N., \& Belém, K. F. (2010). 0 processo de morte na unidade de terapia intensiva neonatal. ConScientia e Saúde, vol. 9, núm. 2, p. 290-299 Universidade Nove de Julho São Paulo. Disponível em: https://www. redalyc.org/pdf/929/92915260017.pdf.

Barbosa, S. M. M., Souza, J.L., Bueno, M., Sakita, N.K., \& Bussotti, E. A. (2008). Período Neonatal. In: Cuidado Paliativo, Cuidado Paliativo / Coordenação Institucional de Reinaldo Ayer de Oliveira. São Paulo: Conselho Regional de Medicina do Estado de São Paulo, p. 689.

Bardin, L. (2011). Análise de conteúdo. São Paulo: Edições 70.

Battikha, E. C., Carvalho, M. T. M., \& Kopelman, B. I. (2014). A formação do neonatologista e os paradigmas implicados na relação com os pais do bebê na unidade de terapia intensiva neonatal. Revista Paulista Pediátrica, 32 (1): 11-6. Disponível em: http://www.scielo.br/pdf/rpp/v32n1/ pt_0103-0582-rpp-32-01-00011.pdf.

Barros, K. G. G., \& Gonçalves, J. R. (2019). Aspectos psicológicos que envolvem cuidados paliativos pediátricos. Revista JGR de Estudos Acadêmicos, ano II, volume II, n5 (ago/dez). Disponível em: http://revistajrg.com/index. php/jrg/article/view/72/66

Cavalcanti, A. E. S., Netto, J. J. M., Martins, K. M. C., Rodrigues, A. R. M., Goyanna, N. F., \& Aragão, O. C. (2018). Percepção de cuidadores familiares sobre cuidados paliativos. Arquivos de Ciências da Saúde, [S.I.], v. 25, n. 1, p. 24-28, abr. ISSN 2318-3691. Disponível em: http://www.cienciasdasaude. famerp.br/index.php/racs/article/view/685.

DATASUS. Brasil, Ministério da Saúde - Sistema de Informações Hospitalares do SUS (SIH/SUS) [homepage da internet]. Informações de Saúde Morbidade Hospitalar do SUS - Por local de internação - Brasil: Óbitos em menores de um ano em 2017. Disponível em: http://tabnet.datasus. gov.br/cgi/tabcgi.exe?sih/cnv/niuf.def.

Gil, A.C. (2008). Métodos e técnicas de pesquisa social. 6 ed. São Paulo: Atlas.

Gonçalves, J. R., \& Santos, M. A. (2019). 0 envolvimento emocional da equipe de enfermagem no processo de morte de recém-nascidos internados em Unidade de Terapia Intensiva Neonatal (UTIN): uma revisão integrativa de literatura. Revista JRG de Estudos Acadêmicos - Ano II, volume II, n.4. Disponível em: https://www.sumarios.org/artigo/envolvimento-emocional-da-equipe-de-enfermagem-no-processo-de-morte-de-rec\%C3\%A9m-nascidos.

Harrop, E., \& Edwards, C. (2013). How and when to refer a child for specialist paediatric palliative care. Arch Dis Child Educ PractEd. Disponível em: http:// dx.doi.org/10.1136/archdischild-2012-303325.

Kóvaks, M. J. (2010). Sofrimento da equipe de saúde no contexto hospitalar: cuidando do cuidador profissional. O Mundo da Saúde, São Paulo: 34(4):420-429. Disponível em: http://www.saocamilo-sp.br/pdf/mundo_saude/79/420.pdf.

Lazarus, R. S., \& Folkman, S. (1984). Stress, appraisal, and coping. Springer, New York.

Lima, K. M. A., Maia, A. H. N., \& Nascimento, I. R. C. (2019) Comunicação de más notícias em cuidados paliativos na oncopediatria. Revista de Bioética. 27 (4). Oct-Dec 2019. Acesso em: 30 de Novembro de 2021. Disponível em: https://www.scielo.br/j/bioet/a/YhCskTrnwMgP5QSzw4RSzFC/?lang=pt.
Mancini, A., Uthaya, S., Beardsley, C., Wood, D., \& Modi, N. (2015). Practical guidance for the management of palliative care on neonatal units. Royal College of Paediatrics and Child Health, ed. 1. Disponivel em: https://www. chelwest.nhs.uk/services/childrens-services/neonatal-services/links/ Practical-guidance-for-the-management-of-palliative-care-on-neonatal-units-Feb-2014.pdf.

Martinho, A. R.; Pilha, L., \& Sapeta, P. (2015). Competências do psicólogo em cuidados paliativos. IPCB: ESALD. P.31. Disponível em: https://repositorio. ipcb.pt/bitstream/10400.11/3103/1/RSL\%20repositorio.pdf

Melo, C. T. V., \& Vaz, P. R. G. (2019). Perda gestacional e neonatal, um sofrimento como outro qualquer. Revista Matrizes, V.13 - № 2 maio/ago. São Paulo. Disponível em: http://www.revistas.usp.br/matrizes/article/ view/148462.

Minayo, M. C. S. (2008). Pesquisa Social: teoria, método e criatividade. 27 ed. Petrópolis, RJ: Vozes.

Neis, M. (2018). Processo decisório sobre cuidados paliativos em unidade de terapia intensiva e pediátrica: comunicação, vivências e sentimentos. Porto Alegre, 241 p., [Dissertação (mestrado)]. Universidade Federal do Rio Grande do Sul. Disponível em: https://lume.ufrgs.br/bitstream/ handle/10183/188721/001085531.pdf? sequence=1\&isAllowed=y

OMS, World Health Organization, (2018). Integrating palliative care and symptom relief into peadiatrics: a Who guide for health care planners, implementers and managers. Geneva, p.5. Disponível em: https://apps. who.int/iris/bitstream/handle/10665/274561/9789241514453-eng. pdf?ua $=1$.

Oliveira, F.C. (2015). Osignificado de cuidados paliativos para enfermeiros que atuam em Neonatologia. Campinas, SP, 90 p., [Dissertação (mestrado)], UNICAMP. Disponível em: http://repositorio.unicamp.br/bitstream/ REPOSIP/283859/1/0liveira_FernandadeCastrode_M.pdf.

Rocha, M. C. P, Souza, A. R., Rossato, L. M., Fossa, A. M., \& Horibe, T. M. A experiência do enfermeiro no cuidado paliativo ao neonato/criança: a interface com o processo de morrer e do luto. Saúde em Revista, Piracicaba, v. 15, n. 40, p. 37-48, abr.-ago. 2015. Disponível em: https://www.metodista.br/ revistas/revistas-unimep/index.php/sr/article/view/2524

Straub, R. 0. (2014). Psicologia da saúde: uma abordagem biopsicossocial. $3^{a}$ ed. - Porto Alegre: Artmed.

Silva, I. N., Salim, N. R., Szylit, R., Sampaio, P. S. S., Ichikawa, C. R. F., \& Santos, M. R. (2017). Conhecendo as práticas de cuidado da equipe de enfermagem em relação ao cuidado na situação de final de vida em recém-nascidos. In: Cuidado ao recém-nascido em fim-de-vida. Escola Anna Nery 21(4). Disponível em: https://www.scielo.br/j/ean/a/mJFKV4HjxZTDLLkxvsb3DBB/?format=pdf\&lang=pt

Silva, M. J. M. (2018). Percepção dos profissionais de saúde sobre os cuidados paliativos neonatais. Repositório Científico do Instituto Politécnico do Viseu, ESSV-UECA. Disponível em: http://repositorio.ipv.pt/bitstream/10400.19/4862/1/MariaJoseMachadoSilva_DM.pdf.

Saporetti, L. A., Andrade, L. Sachs, M. F. A., \& Guimarães, T. V. V. (2012). Diagnóstico e abordagem do sofrimento humano. Manual de cuidados paliativos. ANCP, São Paulo, p. 42-56.

Savoia, M. G., Santana, P. R., \& Mejias, N. P. (1996). Adaptação do inventário de Estratégias de Coping de Folkman e Lazarus para 0 português. Psicologia. USP, São Paulo, v. 7, n. 1-2, p. 183-201. Disponível em: http://pepsic.bvsalud.org/scielo.php?script=sci_arttext\&pi$d=$ S1678-51771996000100009\&lng=pt\&nrm=iso. 